\title{
Self-perceived intrinsic and extrinsic differences between Infor- mation Systems and Computer Science university students
}

\author{
P.M. Alexander*, Hugo H. Lotriet*, Vreda Pieterse ${ }^{\dagger}$ \\ * School of Computing, University of South Africa, South Africa \\ †Dept of Computer Science, University of Pretoria, Pretoria, South Africa
}

\begin{abstract}
Strong arguments exist that the sub-disciplines of Information Systems (IS) and Computer Science (CS) can be meaningfully distinguished, and the literature indicates that teams in which there are variety of personalities and divergent career interests are more likely to successfully complete computing projects. This paper set out to identify differences in terms of personality and career objectives between those entering universities with the intention of pursuing a career in CS and those intending to study IS. First-year students from South African tertiary institutions in 2010 and 2012 were studied in terms of self-reported personality factors (using the Five Factor Model as frame of analysis) as well as perceived environmental factors associated with career choice. Surprisingly, the only persistent significant difference found was that IS students consider well-paid employment as soon as possible after graduating to be more important than CS students do. In terms of the other factors studied no significant differences were found to occur in both years for which data was analysed. Hence, the results show that combining data collected from the students studying different sub-disciplines of computing is justified for research that specifically studies personality or factors such as interest, self-efficacy, career outcomes and how the career choice impacts on quality of life. At a practical level, the findings inform efforts in attracting, retaining and teaching students in these sub-disciplines.
\end{abstract}

KEYWORDS: Career choice, Five Factor Model, computing careers

CATEGORIES: • Social and professional topics $\rightarrow$ Information systems education • Social and professional topics $\rightarrow$ Computer science education

\section{INTRODUCTION}

\subsection{Background}

Different associations and institutions who are actively involved in education related to computers (or computing) identify different sub-disciplines within that broad field.

...there is no question that computing

in the 21st century encompasses many vital disciplines with their own integrity and pedagogical traditions. [1, p. 1]

The Accreditation Board for Engineering and Technology (ABET) identifies three sub-disciplines, namely Computer Science (CS), Information Systems (IS) and Information Technology (IT) [2] and ACM/AIS curriculum recommend-ations exist for IS, CS, computer engineering $(\mathrm{CE})$, software engineering (SE) and IT [3]. These not only have different curricula, they prepare students for different careers 4, have different admission criteria [5] and in South Africa (SA) are packaged with courses from different colleges (as in Britain, in SA these are known as faculties). Hence in SA universities IS courses are generally packaged with

Email: P.M. Alexander alexapm@unisa.ac.za those from the Economic and Management Sciences while CS requires more mathematics and is offered as a Natural Science. (This is also the case in other countries [6]). However, there is quite a lot of overlap between the sub-disciplines, for example computer programming is usually taught in all of them, but to different levels of expertise and often teaching different programming languages [6].

It is possible to conceptualize a common core for multiple programs, and in fact, such shared core courses are taught at a number of institutions. [3, p. 34]

Noticeable in the ACM 2010 IS curriculum is the reduced overlap with application implementation now an elective module [3]. Nevertheless, there appears to be confusion as to the differences between the different sub-disciplines, particularly among prospective students and their parents and possibly others who advise them on careers 4] [5].

In SA universities, a single department frequently offers CS, IS and in some cases also IT. This is justified to some extent, but does add to the blurring of distinctions between the sub-disciplines and the confusion on the part of prospective students.

There seems to be an interesting tension line emerging from the available literature discussing computing 
careers, curricula and the nature of the related professions. On the one hand there is a strong differentiation in terms of conceptualization of the nature of careers and curricula between IS and CS. On the other hand, studies related to career choice and basic tendencies and personality tend to lump those who have chosen any of these careers together in a single group, designating them ICT/ IT or computing professionals / practitioners / students [7]. Whereas some academic research relating to attracting students into particular courses does look at CS and IS separately [6, a significant proportion of this research looks at computing in general. For example, Heinz and $\mathrm{Hu}$ seem to mean the full spectrum of computing when they refer to IT [8] and Lent and various co-authors [7] 9] also study this more general group.

To complicate matters further, studies that examine personality in the computing work environment often combine the sub-disciplines under a label such as "IT teams" ([10, Heinström cited by [4]) and argue for diversity in terms of the composition of the teams. Similarly, national reports usually look at the problem from the employers' perspective and link data to job titles and not a qualification.

This gives rise to the question: Given that strong arguments exist that the sub-disciplines of IS and CS can be meaningfully distinguished, and given the arguments in literature that indeed divergent personalities and divergent career interests are desirable in terms of the successful completion of computing projects, can any meaningful differences be distinguished between those entering universities with the intention of pursuing a career in either of these disciplines? Are these students essentially similar in terms of both intrinsic and extrinsic factors? Is it valid to lump them together for the purpose of career choice and personality studies or, for academic and research purposes, should they be treated as separate groups with different personality traits and career expectations? On the other hand, if they are dissimilar in terms of intrinsic and extrinsic factors, what are the implications for career choice advice, marketing of the different fields of studies, etc.? And should the groups of students found studying the two disciplines be similar or does mis-marketing and bad advice result in students not "finding" the discipline that would fit them best?

This paper compares the perceptions of students taking CS or IS regarding personal ("intrinsic" factors and values) and environmental ("external" or "extrinsic" factors). The Five Factor Model (FFM) is used to analyse how these students describe their own personalities. Other personal aspects (interest and self-efficacy) are analysed separately as are values (related to quality of life, social and ethical issues). Environmental factors have been probed from the perspective of what these students consider to be important in terms of career expectations. These different points of view allow us to look at matters of importance to the students as well as their expectations regarding the world of work that our courses are preparing them for.
The findings of this paper contribute both at conceptual and at everyday knowledge levels. At a conceptual level it adds to our understanding of whether significant differences exist between sub-groups within the larger group of "computing students". This will inform the choice of unit of analysis in career and vocational research. At the everyday level the findings of the study are important for these computing disciplines when trying to attract new students, retain them, as well as refining teaching methods. These are three problem areas that are noted repeatedly in research looking at career choice related to computing and are also highlighted in national reports related to the shortage of ICT skills in various parts of the world. The Australian Computer Society CEO, Alan Patterson, recently repeated this call:

More research needs to be done to understand why, despite the ever more compelling opportunities of ICT, not enough students are choosing ICT as a career [1]

\subsection{ICT skills shortage}

The underlying rationale for this study and related research are two interdependent problems:

- In most countries and at various times universities experience noticeable drops in the number of students enrolling for the various computing sub-disciplines

- In many countries there are persistent reports that there insufficient numbers of people available with the required skills to occupy specialist ICT or computing positions in commerce and industry. Clearly, drops in university enrolments exacerbate the skills shortage three or four years later, but the shortage of some ICT skills seems to be persistent even during economic down turns. Recent evidence of the extent of these problems is most easily obtained from white papers and newspaper reports, as academic research into the reasons for low student enrolment and skills gaps and mismatches between course content and employer requirements lags behind such reports. Three annual reports from United States, United Kingdom and SA and two special reports, from Australia and Ireland will form the basis of the discussion that follows.

Access to sufficient numbers of people with up-todate and advanced ICT skills is extremely important to national economies and, in countries that have succeeded in establishing themselves as technology hubs, many jobs can be created:

Reports investigating the relationship between the effective application of IT and improved productivity found increased investment in ICT capital to have played a major role' in the doubling of US productivity growth rates - commonly referred to as the productivity miracle'. [12, p. 2]

South Africa (SA) is reported by the Media, Information and Communication Technologies Sector Education and Training Authority, (MICT SETA), as also experiencing an ICT skills shortage [13]. 
Table 1: The level of demand for the top twelve scarce skills (potential vacancies - occupations) in the Information Technology sub sector 2012-2015 13.

\begin{tabular}{|l|l|}
\hline OFO Code and Occupation Description & $\begin{array}{l}\text { Total } \\
\text { Scarce } \\
\text { Skills, } \\
\end{array}$ \\
$2012-2015$ \\
\hline 251201 Software Developer & 493 \\
251203 Developer Programmer & 451 \\
252301 Computer Network and Systems En- & 402 \\
gineer & \\
251101 ICT Systems Analyst & 351 \\
351301 Computer Network Technician & 220 \\
422206 Call or Contact Centre Agent & 220 \\
351201 ICT Communications Assistant & 186 \\
251901 Quality Assurance Analyst (Comput- & 152 \\
ers) & \\
252101 Database Designer and Administra- & 76 \\
tor & 72 \\
251202 Programmer Analyst & 67 \\
242101 Management Consultant & 63 \\
133102 ICT Project Manager & 2753 \\
\hline
\end{tabular}

Table 1 shows the MICT SETA's predictions of total scarce skills, 2012-2015, but it is not clear where this is the annual short fall or the total for four years [13. MICT SETA figures are often cited by other sources as clear evidence that there is in fact a shortage of ICT graduates (for example, 14]). Clear evidence in terms of exact numbers is, however, difficult to obtain [15].

Supporting evidence of the ICT skills shortage in SA comes from the World Economic Forum's ereadiness rankings. Mitrovic et al. [16] say that SA has dropped from 47 th in 2007 to 70 th in 2013. However, in terms of Networked eReadiness it improved marginally from 72nd in 2011 to 70 th in 2012 [17. Nevertheless, in the Readiness subindex and the associated pillars (Infrastructure and digital content, Affordability, Skills) South Africa ranks very low (95th of 144 countries) with the Skills pillar pulling down the scores as it is ranked 102. As a matter of comparison, our neighbours (Botswana, Lesotho, Mocambique, Swaziland, Namibia) are all worse than that but Zimbabwe is ranked 87 due to exceptional affordability [17].

Although in 2012 South Africa ranked highest of all African countries in term of Technological readiness, Innovation and in the Global Competitiveness Index (GCI), Africa as a whole lags behind all other continents on all the indices used in the GCI report [18. According to this same report, the most serious challenge facing South Africa in terms of competitiveness is an "Inadequately educated workforce" [18.

\subsubsection{University computing courses and computing ca- reer research}

In 2012 many countries indicated small increases in enrolment in computing courses. The Taulbee survey is published annually for US and Canada and looks separately at CS, IS and CE. In the 2011/2012 report a fourth successive year of increases in "computing majors among US CS departments" is noted [19] [20] and "these data suggest increased in interest in undergraduates computing degrees of all types in the US" [20, p. 11]. The results from Canada given in these same reports seemed less clear. It has been suggested that the increase in interest in computing in the US is in response to high media coverage of Steve Jobs and Mark Zuckerberg.

The numbers of students enrolling for Bachelor degrees in computing at Australian universities has stabilized and includes a large number of foreign students 21. However Australia's Vocational Education and Training (VET) system qualifications decreased by $24.4 \%$ between 2009 and 2010 [22. Enrolments in lower level certificate programmes in Australia are decreasing whilst enrolments for higher qualifications are increasing [22]. It is important to note that significant training occurs outside the publicly funded VET system and is not reflected in these figures. This highlights another aspect of the universal problem with statistics relating to demand and supply for ICT skills referred to earlier. They are rarely complete and hence not accurate [23].

Ireland has identified its ICT skills shortage as being a matter of national importance [24] and many proposals have been accepted by the education ministry of that country including introducing conversion courses [25]. Specific recommendations from the review of the Information Communication Technology (ICT) skills demand in Ireland include improving Mathematics standards at primary and secondary schools and changing the teaching of computing at schools from simply using computers to creating applications:

it was no longer sufficient for students to be familiar with ICT. They need to be engaging in the creative, productive use of ICT facilities. 24]

As in SA, dropout rates in ICT courses such as computing and electronic engineering are considered to be high in Ireland and the low level of Maths proficiency is believed to be the main reason 24.

Many commentators, including the ACS, point out that despite increasing enrolments over the past three or four years, enrolment and completion figures worldwide are still far below those of a decade ago (about 50\% for domestic candidates in Australia) [1]. Suggestions, many similar to those in Ireland, are being made regarding what should be done in terms of education and advice before students make career choices, not only to attract larger numbers of new entrants into the computing professions but also to attract the best possible candidates [11].

eSkills UK reports a very similar pattern to those described above [12]. A number of statistics show that although the increase in computing enrolments is heartening this has still nowhere near reached the peak numbers (in the case of UK there has been a $24 \%$ increase over the period 2007 to 2010 but this is still $28 \%$ lower than the all-time high in 2002). To put this in context, the total number of applicants to 
all higher education courses in the UK has increased by $51 \%$ (Engineering, Biological Sciences and Physical Sciences grew by $35 \%, 41 \%$ and $34 \%$ ) in this same period. Computing has, therefore lost a great deal of ground. In addition, the IT professional workforce in the UK grew by $10 \%$ over that period.

Therefore, the issue that emerges is of interest worldwide, to academia and industry, and requires understanding of the demand for and supply of human resources in computing. Much of the research undertaken while student enrolments were dropping, studied factors that influence career choice, attracting new students and retaining them. This remains important since the recovery in terms of increased interest in taking university computing courses is modest and the deficit in relation to other disciplines and the job market is still quite large.

\subsection{Structure of this paper}

After the introduction, we very briefly discuss the specific theory used, namely the Five Factor Model. A short review of literature specifically comparing IS students with CS students follows. This is followed by a detailed Research Methodology section in which the use of both quantitative and qualitative data in this research is explained. We then present our results in which data collected from Computer Science students is compared with that from Information Systems students for two separate years. The results are discussed and finally conclusions are drawn.

\section{THEORY}

\subsection{Personality research}

Personality factors are used to describe and explain individual differences in how people think, feel, and behave in different situations. Personality remains stable over time 26]. Researchers have proposed a wide variety of personality constructs supported by research that confirms their validity. Hence there are a number of well-known theories of personality. Two prominent current theoretical approaches in vocation-related research are Holland's RIASEC model and the FFM [27] 28. Holland's model focusses on vocational interests while the focus of the FFM is on personality traits but there obviously are linkages and similarities between these models and their constructs. The development of the FFM can be credited to Tupes and Christal (1961, cited by 29]) and was brought into personality research by Norman 30. However it became more popular after Costa and McCrae proposed their NEO Personality Inventory in 1985 31. This inventory was revised to measure personality in terms of the currently accepted FFM 32 .

Studies regarding distinctive personality characteristics of people pursuing careers in computing or scientific fields have been conducted based on several of the personality theories. The Myers Briggs Type Indicator (MBTI) has been used in many studies (e.g. 33. 34 [35] 36] 37]). There have also been studies conducted based on Holland's RIASEC model (e.g., 38 39]). Other models have also been used such as the study by Wynekoop and Walz [40 using Gough and Heilbrun's Adjective Checklist (ACL); one by Ferratt and Short 41 based on the thinking frame of Lewin; Blignaut and Naude 42 considered Boyd's DISC (dominant, influencing, steady and compliant) model.

FFM studies have focused on correlating personality attributes with success in specific computing activities, e.g. with programming performance [43, with tasks specific to some stages in the software development process 44], and with teamwork in Software Engineering [45]. More recently it has been used to study technology acceptance and use [46] 47] 26] and particularly on individuals' use of social networks and other online applications [4]. An extremely important aspect is the issue of personality traits and career satisfaction 49 . Previous research has also been done comparing self-reported personality descriptors of students majoring in computing with those of noncompeting [50. Despite the variety of research already done, several researchers have called for further research on the influence of personality in IS research, (for example, Maier [51] cites [52]; Heinström as cited by [4]; and Devaraj et al. [47]).

\subsection{Choice of FFM for this study}

Maier 51] categorizes IS research on personality according to three levels, namely higher-order traits (the five dimensions of FFM and cognitive style), narrow traits (which are similar to the facets and level descriptors given in Table 2), and IT-specific narrow traits (such as anxiety towards technologies, computer playfulness, personal innovativeness in IT).

The FFM is considered by some researchers to be "the most useful taxonomy in personality research" (Barrick et al. 2001 cited by [47]) and has been widely accepted. This is partly because of its proven ability to explain findings and its concise but comprehensive framework [4]. Although IT-specific narrow traits might be more susceptible to change over time than the high-order traits, both sets of Maier's narrow traits can be considered to be covered by the 5 FFM high level dimensions.

Costa and McCrae generated an enormous amount of research, co-authoring with many prominent personality theorists, to determine correlations between a variety of established theories and their version of the FFM. Research involving the FFM continues and it is evident that the FFM will play a prominent role in personality research for the time being, especially as it is often used as a benchmark and enables meta-research. It is for this reason that the FFM was considered to be appropriate for our research but, based on our previous research [50], we have added a further factor, $V+$ which indicates a tendency to stress values and spirituality (descriptors used are Authentic, Belief, Believer, Christian, Fair, Family, Honest, Moral, Religious, Sincere, Spiritual, Truthful). 
Table 2: The FFM with facets and descriptors

\begin{tabular}{|c|c|c|c|}
\hline Description & Facets & \multicolumn{2}{|l|}{ Level descriptors } \\
\hline \multicolumn{2}{|l|}{ Non-neuroticism } & $N+$ & $N-$ \\
\hline $\begin{array}{l}\text { Identifies level of } \\
\text { proneness to } \\
\text { psychological distress }\end{array}$ & $\begin{array}{l}\text { Anxious } \\
\text { Angry, hostile } \\
\text { Depressed } \\
\text { Self-conscious } \\
\text { Impulsive } \\
\text { Vulnerable }\end{array}$ & $\begin{array}{l}\text { Relaxed, calm, secure } \\
\text { Composed } \\
\text { Slow to be discouraged } \\
\text { Confident } \\
\text { Resist urge } \\
\text { Handle stress easily }\end{array}$ & $\begin{array}{l}\text { Worrying, uneasy, ner- } \\
\text { vous } \\
\text { Quick to feel angry } \\
\text { Easily discouraged } \\
\text { Easily embarrassed } \\
\text { Easily tempted } \\
\text { Sensitive, difficulty cop- } \\
\text { ing }\end{array}$ \\
\hline \multicolumn{2}{|l|}{ Extraversion } & $E+$ & $E-$ \\
\hline $\begin{array}{l}\text { Quantity and intensity } \\
\text { of energy directed } \\
\text { outwards into the social } \\
\text { world }\end{array}$ & $\begin{array}{l}\text { Warm } \\
\text { Assertive } \\
\text { Gregarious } \\
\text { Active } \\
\text { Seek excitement } \\
\text { Positive }\end{array}$ & $\begin{array}{l}\text { Affectionate, friendly } \\
\text { Speaks up } \\
\text { Prefers company, outgo- } \\
\text { ing } \\
\text { Vigorous pace } \\
\text { Craves excitement, ener- } \\
\text { getic } \\
\text { Cheerful, optimistic }\end{array}$ & $\begin{array}{l}\text { Reserved, formal } \\
\text { Stay in background, shy } \\
\text { Solitary, withdrawn } \\
\text { Leisurely pace } \\
\text { Low need for thrills } \\
\text { Less exuberant }\end{array}$ \\
\hline \multicolumn{2}{|l|}{ Openness to experience } & $O+$ & $O-$ \\
\hline $\begin{array}{l}\text { The active seeking and } \\
\text { appreciation of } \\
\text { experiences for their own } \\
\text { sake }\end{array}$ & $\begin{array}{l}\text { Fantasy } \\
\text { Aesthetics } \\
\text { Feelings } \\
\text { Actions } \\
\text { Ideas } \\
\text { Values }\end{array}$ & $\begin{array}{l}\text { Imaginative, inventive } \\
\text { Appreciate art and } \\
\text { beauty } \\
\text { Values all emotions } \\
\text { Prefers variety, tries new } \\
\text { things } \\
\text { Broad intellectual curios- } \\
\text { ity } \\
\text { Open to re-examining val- } \\
\text { ues }\end{array}$ & $\begin{array}{l}\text { Focus on 'here and now' } \\
\text { Appreciate practical } \\
\text { value } \\
\text { Discount feelings } \\
\text { Prefers familiarity, cau- } \\
\text { tious } \\
\text { Narrow intellectual focus } \\
\text { Dogmatic, conservative }\end{array}$ \\
\hline \multicolumn{2}{|l|}{ Agreeableness } & $A+$ & $A-$ \\
\hline $\begin{array}{l}\text { The kinds of interactions } \\
\text { preferred, from } \\
\text { compassion to } \\
\text { tough-mindedness }\end{array}$ & $\begin{array}{l}\text { Trusting } \\
\text { Straightforward } \\
\text { Altruistic } \\
\text { Compliant } \\
\text { Modest } \\
\text { Tender-minded }\end{array}$ & $\begin{array}{l}\text { See others as honest } \\
\text { Frank } \\
\text { Friendly, helpful } \\
\text { Yields under conflict, de- } \\
\text { fers } \\
\text { Self-effacing, humble } \\
\text { Empathetic, compassion- } \\
\text { ate }\end{array}$ & $\begin{array}{l}\text { Cynical, sceptical } \\
\text { Guarded, stretches truth } \\
\text { Reluctant to get involved } \\
\text { Aggressive, competitive } \\
\text { Feels superior to others } \\
\text { Hard-headed, rational }\end{array}$ \\
\hline \multicolumn{2}{|l|}{ Conscientiousness } & $C+$ & $C-$ \\
\hline $\begin{array}{l}\text { Organisation, } \\
\text { persistence, control and } \\
\text { motivation in } \\
\text { goal-directed behaviour }\end{array}$ & $\begin{array}{l}\text { Competent } \\
\text { Orderly } \\
\text { Dutiful } \\
\text { Achieving } \\
\text { Self-disciplined }\end{array}$ & $\begin{array}{l}\text { Efficient, capable \& effec- } \\
\text { tive } \\
\text { Well-organised, neat, } \\
\text { tidy } \\
\text { Reliable } \\
\text { Driven to be successful } \\
\text { Focused on completing } \\
\text { tasks }\end{array}$ & $\begin{array}{l}\text { Feels unprepared } \\
\text { Disorganised, unmethod- } \\
\text { ical } \\
\text { Easy-going } \\
\text { Low need for achieve- } \\
\text { ment } \\
\text { Procrastinates, careless }\end{array}$ \\
\hline
\end{tabular}


Although the FFM is widely accepted, there are some differences in naming the five factors and different scholars interpret the meaning of the individual factors differently. Table 2 summarises our understanding of the FFM and identifies code families created for analysing our data. The factors and their facets have mainly been taken from Costa and McCrae [32, factor descriptions originate from Costa and Widiger (2002, cited in [53]), while level descriptors are as defined by Howard and Howard 54.

\section{CAREER CHOICE LITERATURE}

Whereas many authors report on factors that influence students to study computing at university, only one paper was found where CS and IS (the authors refer specifically to MIS) were compared [6]. Downey and co-authors found that, compared with CS students, MIS students are more influenced by others regarding their career choice and also they want a future career where they interact with people. Therefore that research indicates that MIS students are more people oriented whereas CS students are more technology oriented. This is in line with other research that compares the combined group of computing majors with non-computing majors [55].

\section{RESEARCH METHODOLOGY}

\subsection{Problem statement}

As noted above, there is a fairly large body of published research that combines data obtained from IS and CS and refers to it as ICT or computing data. The question has arisen as to whether this combined sample is sufficiently homogeneous to justify conclusions about "computing majors" as a single group or about "computing majors" versus "non-computing majors". The research reported here compares CS and IS students in order to verify whether combining data from these two sources is justifiable.

In addition there is often a question when students select majors regarding which of the two sub-disciplines would best "fit" a particular student. It is generally believed that students are most likely to do well studying courses that they are interested in [5] [8] and believe will lead to satisfactory and satisfying careers. For example, social cognitive career theory studies the processes through which

...people develop educational / vocational interests, make career-relevant choices, and achieve performances of varying quality in their educational and occupational pursuits.s" 56

\subsection{Hypotheses}

This research sets out to test two hypotheses:

H1. There is no difference between Information Systems majors and Computer Science majors in terms of personality.
H2. There is no difference between Information Systems majors and Computer Science majors in terms of factors that influence career choice.

\subsection{Research design}

This research looks at two significant measures, firstly how the students describe their own personalities and secondly how important identified career outcomes are in influencing the career choice of these students. The first, personality, is a personal (intrinsic) characteristic whereas the perceived importance of career outcomes is extrinsic. Looking at the students from these different points of view is a form of triangulation and strengthens the finding as to whether they can in future be treated as a single unit of analysis in career choice research (i.e. they are to all intents and purposes similar), they are only similar in some respects, or they are entirely dissimilar.

The research, while having the narrower goals described in the hypotheses above, aims to contribute more broadly to research regarding the ICT skills gap by validating a research method (can data from the different sub-disciplines justifiably be used in a single sample) and by obtaining a deeper understanding of both intrinsic and extrinsic motivating factors.

\subsection{Data collection}

A large quantity of research data was collected annually from 2009 to 2012 using questionnaires given to first year students taking introductory courses offered by a number of different universities in SA. These universities were specifically invited to participate so that the sample would include data from a large, wellestablished urban ("advantaged" in SA terminology) university, two far less well-resourced and more rural universities, two different universities of technology and one extremely large university that teaches entirely via distance education. Although not all of the universities participated every year the analysis includes data for 2010 and 2012 from each type of university other than the distance university - reasons for this exclusion are given below. IS departments, CS departments, departments that describe themselves as Information Technology (IT) or Computing Schools participated.

For this study, data from 2010 and 2012 were analysed separately. These years were chosen as previous research noted some interesting changes regarding career choice that might be linked to the economic situation [57. Therefore we chose years after the down turn of 2008 when the situation related to jobs could be considered to be fairly stable. Two separate years were selected to compensate for any on-going market-related effects.

In addition, preliminary analysis showed that the intended final qualification (diploma or degree) and the mode of instruction (distance or classroom) noticeably influence career choice and would probably mask results. Therefore, in order to reduce the number of independent variables we excluded data from students 
Table 4: Questions used to collect quantitative data

\begin{tabular}{|c|c|c|}
\hline \multicolumn{2}{|l|}{ Category } & Question \\
\hline \multirow{3}{*}{ Intrinsic } & Interest & $\begin{array}{l}\text { Interest in the subject - this is the kind of work you want } \\
\text { to do } \\
\text { Job satisfaction: there will be a sense of accomplishment }\end{array}$ \\
\hline & Self-efficacy & $\begin{array}{l}\text { The fact that I am able to master this subject and others } \\
\text { find it too difficult will give me a career advantage } \\
\text { I expect to do well at university } \\
\text { My performance in high school subjects }\end{array}$ \\
\hline & Computer self-efficacy & $\begin{array}{l}\text { I have lots of self-confidence in working with computers } \\
\text { I am confident I could teach someone to use a software } \\
\text { package }\end{array}$ \\
\hline \multirow{3}{*}{$\begin{array}{l}\text { Career } \\
\text { outcomes - extrinsic }\end{array}$} & Short-term prospects & $\begin{array}{l}\text { Good prospects in obtaining a first job without any prior } \\
\text { experience } \\
\text { Good prospects for a better than average starting salary }\end{array}$ \\
\hline & Long-term prospects & $\begin{array}{l}\text { Good long-term salary prospects } \\
\text { A good image / status in the chosen profession } \\
\text { Good prospects for promotion and professional develop- } \\
\text { ment } \\
\text { Job security }\end{array}$ \\
\hline & Flexibility & $\begin{array}{l}\text { A flexible work schedule } \\
\text { Opportunities to work overseas } \\
\text { Different tasks at different times (variety) } \\
\text { Opportunities to work in different kinds of businesses }\end{array}$ \\
\hline Values & Quality of life & $\begin{array}{l}\text { Balance between social and family activities and work } \\
\text { My chosen career will be quite easy } \\
\text { My chosen career will not be very stressful } \\
\text { Having a job where I work with people } \\
\text { Opportunity to 'give back' to my community in some way } \\
\text { Being able to combine career and family } \\
\text { My career will give meaning to my life }\end{array}$ \\
\hline
\end{tabular}

Table 3: Number of respondents

\begin{tabular}{|l|l|r|r|}
\hline & Sex & IS & CS \\
\hline \multirow{5}{*}{2010} & Female & 38 & 84 \\
& Male & 47 & 215 \\
& Not given & 3 & 9 \\
& Total & 88 & 309 \\
\hline \multirow{5}{*}{2012} & Female & 31 & 37 \\
& Male & 49 & 170 \\
& Not given & 0 & 0 \\
& Total & 80 & 207 \\
\hline
\end{tabular}

who were studying via distance education and those who were studying for diplomas rather than degrees.

Finally data was only used from students who clearly indicated that they were intending to take CS or IS as a 3rd year major. Students intending to study both CS and IS, those studying other computingrelated degrees, such as computer engineering, and the very large number whose major subjects are not computing related, such as those studying for Financial Sciences degrees, were excluded. No random sampling or balancing of the sample was done and hence the composition of the sample used is a true reflection of the students taking the courses. Hence there are more than twice as many males as females in the total sample $(38+84+31+37=190$ females and $47+215+49+170=481$ males) and just over three times as many CS students as IS (515 CS and 168 IS) (see Table 3).

The questionnaires were made available to students as early in the academic year as the various departments could manage. The questions used had the following formats:

Q. How important was the following in influencing you to choose the career that your chosen qualification prepares you for: ...?

Table 4 lists questions in this format. These questions were derived from several published sources, most notably three papers published in $2007 / 2008$ in the Journal of Information Systems Education [58] 59] [60] but were reworded slightly and, since not all of the original questions used by those authors matched our needs, some were omitted. A Likert scale from 1 (totally unimportant) to 6 (extremely important) was used. Option 7 was "Do not know or have not really thought about it".

The questions have been grouped in Table 4 as intrinsic, extrinsic and values. Intrinsic questions are related to self-efficacy and interest in the subject. Extrinsic questions relate to expected career outcomes. Value questions have ethical or social implications. (These quantitative questions are general and can be asked of any student. Even computer self-efficacy is relevant in an increasing number of careers. They were, however, obtained from (and adapted / reworded in 
some cases) other published IS research [58, 59] and similar questions are commonly used. However, in some IS research more explicitly IS oriented questions are posed (for example Zhang [60]).

Q. Give any five words to describe your personality. The strength of the approach followed in collecting the qualitative data was that this data represented the respondents' opinions without imposing a theory or a framework 61.

This research is multi-methodological: the quantitative data is analysed using straightforward statistics (using IBM SPSS Statistics 20) whereas the students' descriptions of their personalities provide qualitative data and this needed more interpretation. Once the erratic spelling was sorted out with help from a spelling checker, Atlas ti (v6) was used to assign codes to individual personality descriptions. In 2010 this was done by two independent coders creating two sets of processed data.

The low level codes from each set were grouped into families of codes corresponding with the personality groups associated with the FFM (see Table 2) and one further factor, $V+$, for ethical or value-based words (e.g. 'truthful'). This eleventh category was added as when we analysed our data in terms of the FFM we came across a significant number of student quotations that related to spirituality and values 62. Examples for some of the five factor facets are shown in Table 5 The authors each did this grouping separately, identified the points of disagreement, reconsidered them in light of their co-researchers' opinions, and eventually reached consensus. The code families were then applied to both sets of coded data and distributions were compared. Intercoder reliability exceeded $95 \%$. Thereafter the output from Altas ti was imported to SPSS for further statistical analysis.

In 2012 two people working independently assigned the new data to the 2010 codes. A few new codes were created as well and these were checked, assigned to families and the process was continued as in 2010. Once again intercoder reliability exceeded $95 \%$.

The possibility that the coding of qualitative data was unduly subjective was addressed through a systematic research protocol that involved coding of raw data (student quotes) by more than one person, and grouping of codes into code families by more than one person. The high level of intercoder reliability that was obtained suggests that the final set of categories used for statistical analysis is largely insensitive to personal bias. Standard statistical procedures were followed for the analysis of all the data once it was categorized.

\section{RESULTS}

\subsection{Qualitative data}

Once the qualitative data was coded, separate statistical analyses were done for the two years to see whether the distribution of personality codes differed between CS and IS students. Table 6 shows significant differences ( $p$-values) obtained when Cross Tab
Table 5: Low level codes grouped in code families

\begin{tabular}{|c|c|}
\hline$A-$ & $\begin{array}{l}\text { Anti-social, Argumentative, Bad temper, } \\
\text { Controlling, Critical, Demanding, Difficult, } \\
\text { Ego, Impatient, Naughty, Poor judge, Sar- } \\
\text { castic, Selfish, Stubborn }\end{array}$ \\
\hline$A+$ & $\begin{array}{l}\text { Accommodating, Agreeable, Appreciative, } \\
\text { Approachable, Caring, Charm, Compassion- } \\
\text { ate, Compromising, Educator, Flexible, For- } \\
\text { giving, Friendly, Generous, Gentle, Giving, } \\
\text { Gracious, Helpful, Humble, Kind, Loving, } \\
\text { Loyal, Non-Judgmental, Non-racist, Obe- } \\
\text { dient, Participating, Patient, Respectful, } \\
\text { Team player, Trusting, Understanding }\end{array}$ \\
\hline \multicolumn{2}{|c|}{ Rows omitted for other facets of the five factors } \\
\hline$O-$ & $\begin{array}{l}\text { Analytical, Cautious, Childlike, Conserva- } \\
\text { tive, Logical, Practical, Realist, Technical }\end{array}$ \\
\hline$O+$ & $\begin{array}{l}\text { Adventurous, Artistic, Brave, Challenge, } \\
\text { Creative, Cunning, Curious, Diverse, } \\
\text { Dreamer, Free, Idealist, Informed, Insight, } \\
\text { Interesting, Intuitive, Learner, Liberal, Ob- } \\
\text { servant, Open-minded, Opportunistic, Prob- } \\
\text { lem solver, Reflective, Resourceful, Sensi- } \\
\text { tive, Spontaneous, Thoughtful, Versatile, } \\
\text { Visionary }\end{array}$ \\
\hline
\end{tabular}

analyses were done for the personality groups. Two significant differences were evident from the 2010 data where $13.1 \%$ of IS students compared to a much higher percentage $(25.75 \%)$ of CS students described themselves in terms that we considered to indicate an $E-$ (not extrovert) personality. At the same time many more 2010 IS students $(71.43 \%)$ considered that they were $E+$ than the $57.19 \%$ of CS students. These differences did not recur in 2012; there were noticeably fewer IS students indicating $E+$ personality traits in 2012 than in 2010. Since care was taken to ensure that coding was similar over the two years, the more serious frame of mind of IS students in 2012 is not easily explained other than that the economic down turn is persisting. In 2012 there were also two categories with significant differences. CS students chose noticeably more descriptors from $N+(55.22 \%$ vs $38.46 \%$ for IS $)$ and for $\mathrm{O}+(43.78 \%$ compared with $29.49 \%$ for IS). Again reasons for changes that occurred only in 2012 are not clear.

The percentages of IS and CS students in 2012 who indicated that any particular factor was extremely important in career choice was used to calculate the relative importance of factors (shown as Rank in Tables 7 to 9. . Rank $=1$ was given to questions indicated as very important, Rank $=9$ for least important. The sequence of questions remains as in Table 4 .

\subsection{Quantitative data}

Tables 7 to 9 also show differences ${ }^{1}$ from analyses of each of the 25 individual questions (given in Table 4 ) similar to analysis for the personality data.

\footnotetext{
${ }^{1}$ In all of these tables, $* *$ indicates $p<0.01$ and $*$ indicates $p<0.05$.
} 
Table 6: Chi squared $p$ values where Cross Tab analyses between CS and IS

\begin{tabular}{|c|c|c|c|c|c|c|c|c|c|c|}
\hline & \multicolumn{5}{|c|}{2010} & \multicolumn{5}{|c|}{2012} \\
\hline & \multicolumn{2}{|c|}{$\begin{array}{r}\text { IS }(N=84) \\
\%\end{array}$} & \multicolumn{2}{|c|}{$\begin{array}{r}\mathrm{CS}(N=299) \\
\%\end{array}$} & \multirow{2}{*}{$\begin{array}{l}p \\
0.809\end{array}$} & \multicolumn{2}{|c|}{$\begin{array}{r}\text { IS }(N=78) \\
\%\end{array}$} & \multicolumn{2}{|c|}{$\begin{array}{r}\mathrm{CS}(N=201) \\
\%\end{array}$} & \multirow{2}{*}{$\begin{array}{l}p \\
0.941\end{array}$} \\
\hline$A-$ & 5 & 5.95 & 20 & 6.69 & & 6 & 7.69 & 16 & 7.96 & \\
\hline$A+$ & 67 & 79.76 & 217 & 72.58 & 0.184 & 54 & 69.23 & 118 & 58.70 & 0.105 \\
\hline$C-$ & 2 & 2.38 & 19 & 6.35 & 0.158 & 0 & 0 & 7 & 3.48 & Too few \\
\hline$C+$ & 44 & 52.38 & 161 & 53.85 & 0.812 & 47 & 60.26 & 129 & 64.18 & 0.542 \\
\hline$E-$ & 11 & 13.1 & 77 & 25.75 & $0.015 * *$ & 13 & 16.67 & 28 & 13.93 & 0.562 \\
\hline$E+$ & 60 & 71.43 & 171 & 57.19 & $0.018^{* *}$ & 32 & 41.03 & 88 & 43.78 & 0.677 \\
\hline$N-$ & 5 & 5.95 & 31 & 10.37 & 0.220 & 5 & 6.41 & 20 & 9.95 & 0.353 \\
\hline$N+$ & 39 & 46.43 & 143 & 46.83 & 0.821 & 30 & 38.46 & 111 & 55.22 & $0.012 * *$ \\
\hline$O_{-}$ & 6 & 7.14 & 17 & 5.69 & 0.619 & 4 & 5.13 & 25 & 12.44 & 0.073 \\
\hline$O+$ & 21 & 25.0 & 90 & 30.1 & 0.363 & 23 & 29.49 & 88 & 43.78 & $0.029 * *$ \\
\hline$V+$ & 11 & 13.1 & 48 & 16.05 & 0.507 & 10 & 12.82 & 23 & 11.44 & 0.749 \\
\hline
\end{tabular}

Table 7: Intrinsic factors: Overall ranking of influences for all students as well as significant difference values $(p)$ for intrinsic factors between IS and CS for 2010 and 2012

\begin{tabular}{|l|l|l|r|r|}
\hline Rank & \multicolumn{1}{|c|}{$\%$} & Question & $\mathbf{2 0 1 0} p$ & $\mathbf{2 0 1 2} p$ \\
\hline 1 & 86 & $\begin{array}{l}\text { Interest - this is the kind of work you want to } \\
\text { do }\end{array}$ & .076 & .078 \\
1 & 87.9 & Job satisfaction - a sense of accomplishment & .204 & .858 \\
3 & 60.1 & $\begin{array}{l}\text { I am able to master this subject while others find } \\
\text { it too difficult - will give me a career advantage }\end{array}$ & .455 & .697 \\
1 & 81.1 & I expect to do well at university & .807 & .656 \\
3 & 66.9 & My performance in high school subjects & .346 & .246 \\
4 & 51.6 & I could teach someone to use a software package & .863 & .158 \\
\hline
\end{tabular}


Table 8: Extrinsic factors: Overall ranking of influences for all students as well as significant difference values (p) for intrinsic factors between IS and CS for 2010 and 2012

\begin{tabular}{|c|c|c|c|c|c|}
\hline & Rank & $\%$ & Question & $2010 p$ & $2012 p$ \\
\hline \multirow[t]{2}{*}{$\begin{array}{l}\text { Short term } \\
\text { prospects }\end{array}$} & 3 & 62.2 & $\begin{array}{l}\text { Good prospects in obtaining a first job without } \\
\text { any prior experience }\end{array}$ & .514 & $.043 *$ \\
\hline & 2 & 76.4 & $\begin{array}{l}\text { Good prospects for a better than average starting } \\
\text { salary }\end{array}$ & $.020 *$ & $.033 *$ \\
\hline \multirow{5}{*}{$\begin{array}{l}\text { Long term } \\
\text { prospects }\end{array}$} & 1 & 81.4 & Good long-term salary prospects & .966 & .195 \\
\hline & 4 & 55.6 & Image / status in chosen profession & .741 & .231 \\
\hline & 1 & 81.1 & $\begin{array}{l}\text { Good prospects for promotion and professional } \\
\text { development }\end{array}$ & .922 & $.027 *$ \\
\hline & 1 & 79.7 & Job security & .728 & .696 \\
\hline & 2 & 76.2 & $\begin{array}{l}\text { A stable career with guaranteed employment in } \\
\text { all economic climates }\end{array}$ & .395 & .083 \\
\hline \multirow{4}{*}{$\begin{array}{l}\text { Flexible } \\
\text { work } \\
\text { environment }\end{array}$} & 4 & 52.3 & A flexible work schedule & .911 & .152 \\
\hline & 3 & 63.7 & Opportunities to work overseas & .957 & .416 \\
\hline & 4 & 54.6 & Variety of tasks at different times & .804 & .448 \\
\hline & 3 & 67.4 & $\begin{array}{l}\text { Opportunities to work in different kinds of busi- } \\
\text { nesses }\end{array}$ & .096 & .272 \\
\hline
\end{tabular}

Table 9: Values factors: Overall ranking of factors for all students as well as significant difference values $(p)$ for value factors between IS and CS for 2010 and 2012

\begin{tabular}{|l|l|l|l|l|}
\hline Rank & $\%$ & Question & $\mathbf{2 0 1 0} p$ & $\mathbf{2 0 1 2} p$ \\
\hline 2 & 71.7 & Balance between social and family activities and work & $.014 *$ & .227 \\
9 & 19.7 & My chosen career will be quite easy & $.004 * *$ & .182 \\
9 & 23.7 & My chosen career will not be very stressful & .561 & .705 \\
4 & 50.2 & Having a job where I work with people & .540 & $.034 *$ \\
4 & 46.2 & Opportunity to "give back" to my community in some way & .439 & .059 \\
3 & 62 & Being able to combine career and family & .481 & .316 \\
3 & 56.7 & My career will give meaning to my life & .104 & .345 \\
\hline
\end{tabular}


Only six of the questions have significantly different data $(p<0.5)$ when IS and CS students are compared. Only one of these was evident in both of the years studied.

Each of these six cases will be discussed below and this discussion includes Tables 10 to 15 which show the percentage of responses per option (low, medium or high importance for that factor in career choice). Tables 10 to 15 also show the $p$-value for the questions in the top left of the table.

The analysis is done on two levels. First we discuss the three "issues" that arise from the six questions with significant differences - related to short term career prospects, long term career prospects and quality of life (values). The analysis continues with questions at a higher level, namely, Intrinsic, Extrinsic and Value factors, where analysis of the quantitative data and qualitative data are brought together.

Table 10: Getting a first job (2010)

\begin{tabular}{|l|c|c|c|}
\hline$p=0.043$ & Low & Medium & High \\
\hline IS & $10.7 \%$ & $16.0 \%$ & $73.3 \%$ \\
CS & $11.8 \%$ & $30.3 \%$ & $57.9 \%$ \\
\hline
\end{tabular}

Table 11: Better than average first salary (2010)

\begin{tabular}{|l|c|c|c|}
\hline$p=0.020$ & Low & Medium & High \\
\hline IS & $9.2 \%$ & $11.5 \%$ & $79.3 \%$ \\
CS & $6.2 \%$ & $25.3 \%$ & $68.4 \%$ \\
\hline
\end{tabular}

Table 12: Better than average first salary (2012)

\begin{tabular}{|l|c|c|c|}
\hline$p=0.033$ & Low & Medium & High \\
\hline IS & $1.3 \%$ & $15.6 \%$ & $83.1 \%$ \\
CS & $10.8 \%$ & $15.3 \%$ & $73.9 \%$ \\
\hline
\end{tabular}

\subsubsection{Issues regarding short term prospects}

Three significant differences, arising from two questions, are related to a first job. CS students believe that these questions are important, but many more IS students think that they are very important when deciding on courses and a career. The first relates to getting a job without having any experience (Table 10). IS students in SA are much more aware of the importance of getting employment than CS students are.

Related to getting a first job, IS students think it is really important that they get a good first salary whereas CS students are not as often greatly influenced by this factor. Starting salary came up in both 2010 (Table 11) and 2012 (Table 12). This is the only issue where there is evidence of a consistent difference between CS and IS students.

\subsubsection{Issues regarding long term prospects}

Only one of the questions related to long term prospects showed a notable difference. As with the issues relating to first jobs, CS students are less worried about subsequent career progress than IS students (Table 13). Comparing students who considered salary and related factors very important (Table 10 13), IS students seem to be more ambitious in terms of financial reward and other aspects of career progress than the CS students are.

Table 13: Promotion \& professional development

\begin{tabular}{|l|c|c|c|}
\hline$p=0.027$ & Low & Medium & High \\
\hline IS & $0.0 \%$ & $10.3 \%$ & $89.7 \%$ \\
CS & $6.4 \%$ & $15.8 \%$ & $77.7 \%$ \\
\hline
\end{tabular}

\subsubsection{Issues regarding quality of life (values)}

Three questions in this group (namely, Balance between social and family activities and work; My chosen career will be quite easy; Having a job where I work with people) produced significant differences (Tables 14 but each of these was only seen in one year. Balance is very important to both sets of students, but in 2010 IS students seemed more extreme (tended to choose low importance or highly important) whereas CS students were more moderate (see Table 14).

Table 14: Balance: Social, Family \& Work

\begin{tabular}{|l|c|c|c|}
\hline$p=0.014$ & Low & Medium & High \\
\hline IS & $9.1 \%$ & $11.4 \%$ & $79.5 \%$ \\
CS & $3.3 \%$ & $21.4 \%$ & $75.3 \%$ \\
\hline
\end{tabular}

Table 15: My chosen career will be quite easy

\begin{tabular}{|l|c|c|c|}
\hline$p=0.004$ & Low & Medium & High \\
\hline IS & $34.5 \%$ & $46.4 \%$ & $19.0 \%$ \\
CS & $46.8 \%$ & $27.3 \%$ & $25.9 \%$ \\
\hline
\end{tabular}

Table 15 shows that neither group thought that it was important how easy the career would be, but in 2010 considerable more CS students thought this was extremely unimportant. In 2012 there was an interesting difference regarding "working with people" CS students considered this much less important than IS students (Table 16). As before we have no real idea as to why these differences occur or why they are not evident in 2010. Environmental and contextual reasons are the most likely contributing factors and these seem to impact differently on IS and CS students so they might be quite localized influences. What we can say is that environment does seem to have a major impact and this is volatile (short lived). As the survey was carried out early in the first year of university the influence of individual lecturers and lectures was limited but cannot be totally discounted.

\section{DISCUSSION}

\subsection{Personality (intrinsic) factors}

In the literature, interest and self-efficacy (both general and computer self-efficacy) are judged to be very 
Table 16: Working with people

\begin{tabular}{|l|c|c|c|}
\hline$p=0.034$ & Low & Medium & High \\
\hline IS & $13.0 \%$ & $24.7 \%$ & $62.3 \%$ \\
CS & $23.0 \%$ & $31.5 \%$ & $45.5 \%$ \\
\hline
\end{tabular}

important personal qualities related to career choice although other people play a significant role in shaping them 63 . In the quantitative analysis reported here there were no significant differences at all between IS and CS students in this group of questions (Table 7).

\subsection{Environmental (extrinsic) factors}

In Table 8 the careers outcomes that are largely to do with material benefits (extrinsic factors) are divided into:

(a) short term prospects

(b) long term prospects

(c) those related to variety and flexibility in the work environment.

We tentatively link a preference for a flexible environment to $\mathrm{O}+$ personalities.

Three of the eleven extrinsic career outcomes questions produced significant differences (Table 8) and these were discussed in 5.2.1 and 5.2.2. Our finding that IS students are more concerned about financial reward both in the short and long term than CS students differs from Downey et al. 6] who found no significant difference. However in our findings there are no significant differences at all between IS and CS students regarding the third group of the extrinsic factors, namely, "flexibility in the work environment". This is confirmed to some extent by the qualitative data (Table 6) as there is no difference in distribution of $\mathrm{O}+$ or $\mathrm{O}-$ personality descriptors between the two groups in 2010 although this does occur in 2012.

\subsection{Values}

This discussion follows on that in section 5.2.3 (Quality of life). As noted there, there are significant differences for three of the seven questions in this group (Table 10, particularly relating to "balance" and "work with people". As noted in Section 3, we discovered only one paper that reports on similar research (comparing IS and CS students) [6]. Our results confirm the reported findings that people are more important for IS than for CS students.

The issue of "My chosen career will be quite easy" does not seem to fit in well as it could be interpreted as a question of self-efficacy, but since it was stated as "How important was the following in influencing you to choose the career that your chosen qualification prepares you for ...?" This and its partner question regarding stress are considered to refer to a quality of life preference.

Although there is some evidence that IS and CS students might differ in terms of a number of factors in this category, it is not repeated in both years and a pattern is not clear. The qualitative $V+$ data associated with quality of life questions also does not reflect these differences (Table 6). Hence we surmise that these differences stem from temporary environmental influences rather than the personal (intrinsic) characteristics of the students.

\subsection{Research hypotheses}

To answer the research questions:

How do Information Systems majors differ from Computer Science majors in terms of personality? There are no clear differences.

How do Information Systems majors differ from Computer Science majors in terms of factors that influence career choice? IS majors consider a better than average starting salary to be more important than CS students from the same SA universities. Other than this, evident differences seem to vary from year to year and the reason for this is unclear as the economic conditions in 2010 and 2012 in SA were similar and no other reasons have been proposed.

Although the quantitative data confirms published research 6] 64, 65, 59] regarding the relative importance of different factors as indicated by the Rank values in Tables 7 9, this was not the purpose of this research and indeed the published research is referred to only in passing in the literature review. There is no clearly discernible pattern found when studying the relatively small number of significant differences between IS and CS students.

\subsection{Persistent results over time}

This research used data from two separate cohorts of students and this gave us the opportunity to check whether findings were repeated in both years.

The fact that there was only one significant difference repeated in the data for both years shows that differences were not persistent despite the economic and employment prospects being fairly similar in both years. Other, more temporary, environmental factors are assumed to have accounted for these differences but these are believed to be local, not in the sense of deriving from specific school environments or the regions from which the students come, but rather as influencing IS and CS students differently.

In the qualitative data there was evidence of differences in terms of $E+, E, N+$ and $O+$ but each of these were only seen for one year. This is surprising as we did not expect temporary, environmental factors to affect the students' descriptions of their own personalities. A more persistent change would indicate that there had been career advice changes regarding what type of personality suits IS or CS or the types of activities that these disciplines involve. Thus, a persistent change would show that new groups of students are being attracted to the subjects based on advice regarding personality rather than extrinsic factors or values. We will look out for this in future data analyses.

One potential avenue for further research in this regard may be to examine the impact that highly reported IT personalities (e.g. Bill Gates or Steve Jobs) 
may have temporarily on perceptions of students selecting these disciplines. Basic tendencies including personality are stable and therefore exist prior to choice of major subject and degree but a student who identifies with a particular role model may want to emphasize the attributes that he or she thinks are expected (or possibly those that they admire in the role model). Hence temporary influences could affect both the choice of qualification and future career and the public persona that the student wishes to project. The "public persona" idea is a slightly different view: since the personality descriptors are self-reported, those reported by an individual may change as a result of what they believe is appropriate (possibly to match a role model) even though the literature is clear that personality does not change over time. Furthermore, although personality differences have been found between computer majors and non-computer majors [50], these "computer personalities" do not seem to be more obvious in IS than in CS majors (or vice versa).

\subsection{Links between quantitative and qualitative data}

In the results section the qualitative data and quantitative data were linked for $O$ and $V$ personality factors. We will now try to justify other links although as before these are tentative. The closest that the set of quantitative questions comes to shedding light on $\mathrm{N}+$ is that the self-efficacy (intrinsic) questions that can be related to optimism and a positive attitude. These quantitative self-efficacy questions have the fewest number of IS/CS differences in both years and hence do not support the difference between CS and IS students in the $2012 N+$ results.

The quantitative and qualitative data cannot be linked in terms of the $E$ factor.

We propose, therefore, that our study shows no obvious, persistent, significant differences in terms of personality or the factors that influence career choice other than for one short term factor, namely importance of getting well paid employment as soon as possible after graduating. The career choice factors were subdivided into, interest and self-efficacy (intrinsic factors), extrinsic factors and values.

\section{CONCLUSION}

In the Introduction we posed a number of informal questions: Can any meaningful differences be distinguished between those entering universities with the intention of pursuing a career in either of these disciplines? Are these students essentially similar in terms of both intrinsic and extrinsic factors? Is it valid to lump them together for the purpose of career choice and personality studies or, for academic and research purposes, should they be treated as separate groups with different personality traits and career expectations? These informal questions were formalized as hypotheses.
Quantitative data and qualitative data from a questionnaire completed by first year students from different universities in SA in two different years were analysed. The qualitative data were self-reported descriptions of the personality of the student and these were coded and then analysed using FFM. The quantitative data reflected how important different intrinsic, extrinsic and value-based factors are.

This research found no clear pattern for the two years relating to significant differences in terms of personality or the factors that influence career choice other than for the short term factor of importance of getting well-paid employment as soon as possible after graduating.

The IS and CS groups value (assign the importance of) intrinsic or personal career factors, as reflected in self-efficacy and interest and all aspects of personality, similarly. The two groups assess the importance of external career factors (extrinsic factors) quite similarly except as noted previously, for the short term factor of importance of finding work once the student qualifies. Finally the two groups were reasonably similar both in their assessment of the value dimension of their personalities and the related quality of life factors.

Therefore, the ultimate conclusion and main contribution from this paper is that it is justifiable to combine data collected from the students studying different sub-disciplines of computing and hence to study computing as a whole both when looking specifically at issues related to personality and when looking at factors more commonly related to career choice such as interest, self-efficacy, career outcomes and how the career choice impacts on quality of life.

In the discussion we tentatively linked some of the extended FFM factors and facets with the career choice questions. For example, a tendency to consider quality of life questions as very important in career choice is proposed as evidence of a $V+$ personality; strong selfefficacy might be more common among people with an $N+$ personality; and an acknowledged preference for a flexible and varied work environment seems consistent with a personality with $\mathrm{O}+$ aspects. However, these relationships have not been shown empirically and this could be proposed as further research.

At a practical level, these findings raise a number of further questions that might prove fruitful avenues for future research. These include examining whether the similarities in the group relate to the way in which these careers are perceived to be similar on the basis of available information to school children (and therefore partially based on ignorance of the significant differences between the disciplines) - this further research relates to the temporary, local environmental factors referred to earlier, and would assist in explaining the fluctuations seen in our data over the two years; understanding the implication for teaching methods in the various disciplines; and understanding the impact on team work and collaboration in the computing workplace. 


\section{REFERENCES}

[1] IEEE. "Computer Science, Final Report, The Joint Task Force on Computing Curricula". IEEE Computer Society and Association for Computing Machinery, IEEE Computer Society, 2001.

[2] A. Y. Akbulut and C. A. Looney. "Inspiring students to pursue computing degrees". Communications of the $A C M$, vol. 50, no. 10, pp. 67-71, 2007.

[3] H. Topi, J. S. Valacich, R. T. Wright, K. Kaiser, J. F. Nunamaker Jr, J. C. Sipior and G.-J. De Vreeda. "IS 2010: Curriculum Guidelines for Undergraduate Degree Programs in Information Systems." Communications of the Association for Information Systems, vol. $26,2010$.

[4] J. Warren, D. Young and K. Williams. "Personality, Gender and Careers in Information Technology." In AMCIS. 2012.

[5] J. Courte and C. Bishop-Clark. "Do students differentiate between computing disciplines?" In $A C M$ SIGCSE Bulletin, vol. 41, pp. 29-33. ACM, 2009.

[6] J. P. Downey, R. McGaughey and D. Roach. "MIS versus Computer Science: An Empirical Comparison of the Influences on the Students' Choice of Major." Journal of Information Systems Education, vol. 20, no. 3, 2009.

[7] R. W. Lent, A. M. Lopez Jr, F. G. Lopez and H.-B. Sheu. "Social cognitive career theory and the prediction of interests and choice goals in the computing disciplines". Journal of Vocational Behavior, vol. 73, no. 1 , pp. 52-62, 2008.

[8] N. Heinze and Q. Hu. "Why college undergraduates choose IT: a multi-theoretical perspective". European Journal of Information Systems, vol. 18, no. 5, pp. 462-475, 2009.

[9] R. W. Lent, F. G. Lopez, H.-B. Sheu and A. M. Lopez Jr. "Social cognitive predictors of the interests and choices of computing majors: Applicability to underrepresented students". Journal of Vocational Behavior, vol. 78, no. 2, pp. 184-192, 2011.

[10] A. R. Peslak. "The impact of personality on information technology team projects". In Proceedings of the 2006 ACM SIGMIS CPR conference on computer personnel research: Forty four years of computer personnel research: achievements, challenges $\& 5$ the future, pp. 273-279. ACM, 2006.

[11] "Declining enrolments and skills shortages threatens future of ICT", 2012. URL http://www . acs.org.au/news-and-media/newsand-media-releases/2012/declining-enrolmentsand-skills-shortages-threatens-future-of-ict.

[12] eSkills UK Sector Skills Council Ltd. "eSkills UK 2012 Technology Insights", 2012.

[13] MICT-SETA. "ISETT SETA Sector Skills Plan for 2011-2016 (Version 2.1)", 2011.

[14] J. Breytenbach and C. de Villiers. "Supply elasticity within the South African ICT labour market". In 5th Annual Pre-ICIS Global Development Workshop. 2012.

[15] H. H. Lotriet, M. C. Matthee and P. M. Alexander. "Challenges in ascertaining ICT skills requirements in South Africa". South African Computer Journal, vol. 46, no. 1, pp. 38-48, 2010.
[16] Z. Mitrovic, W. Taylor, M. Sharif, W. Claassen, H. Wesso et al. "E-social Astuteness skills for ICTsupported equitable prosperity and a capable developmental state in South Africa". International Journal of Education and Development using ICT, vol. 9, no. 3, 2013.

[17] B. Bilbao-Osorio, S. Dutta, T. Geiger and B. Lanvin. "The Networked Readiness Index 2013: Benchmarking ICT Uptake and Support for Growth and Jobs in a Hyperconnected World". The Global Information Technology Report, pp. 3-34, 2013.

[18] World Economic Forum. The Africa Competitiveness Report 2013. World Bank, 2013.

[19] S. Zweben. "Computing degree and enrollment trends". Computing Research Association, 2011.

[20] S. Zweben and B. Bizot. "2011 Taulbee Survey: Continued Increase in Undergraduate CS Degree Production; Slight Rise in Doctoral Production". Computing Research Association, vol. 24, no. 3, pp. 7-24, 2012.

[21] C. Mate. "ICT labour market indicators: An overview of the demand and supply sides of the ICT labour market in Australia". Department of Education, Employment and Workplace Relations, Australia, n.d.

[22] IBSA. "IBSA environment scan 2012", 2012. URL http://www.ibsa.org.au/Portals/ibsa org.au/docs/Research\&DiscussionPapers/Escan/ EScan2012/IBSAEscan2012-ICT.pdf

[23] P. Alexander, H. Lotriet and M. Matthee. "Methodological challenges in e-skills shortage research in South Africa". In Proceedings of the 2009 Annual Research Conference of the South African Institute of Computer Scientists and Information Technologists, pp. 16-21. ACM, 2009.

[24] Joint Committee on Jobs Enterprise and Innovation. "A review of the Information Communication Technology (ICT) skills demand in Ireland". Houses of the Oireachtas, 2012.

[25] Department of Education and Skills Ireland. "Minister Quinn announces additional higher education places to address ICT skills shortage". Press release, 16 November 2012.

[26] C. Maier. "Explaining the influence of user personality on the evaluation of it usage drivers and it usage consequences". In Proceedings of the 49th SIGMIS annual conference on Computer personnel research, pp. 86-90. ACM, 2011.

[27] M. R. Barrick, M. K. Mount and R. Gupta. "Metaanalysis of the relationship between the five-factor model of personality and Holland's occupational types". Personnel Psychology, vol. 56, no. 1, pp. 45-74, 2003.

[28] E. W. Cotter and N. A. Fouad. "The relationship between subjective well-being and vocational personality type". Journal of Career Assessment, vol. 19, no. 1, pp. 51-60, 2011.

[29] N. Taylor. The construction of a South African fivefactor personality questionnaire. Ph.D. thesis, Rand Afrikaans University, 2008.

[30] W. T. Norman. "Toward an adequate taxonomy of personality attributes: Replicated factor structure in peer nomination personality ratings." The Journal of Abnormal and Social Psychology, vol. 66, no. 6, p. 574, 1963. 
[31] I. T. Robertson and A. Kinder. "Personality and job competences: The criterion-related validity of some personality variables". Journal of Occupational and Organizational Psychology, vol. 66, no. 3, pp. 225-244, 1993.

[32] P. T. Costa and R. R. McCrae. "Normal personality assessment in clinical practice: the NEO Personality Inventory." Psychological assessment, vol. 4, no. 1, p. 5, 1992 .

[33] L. F. Capretz and F. Ahmed. "Making sense of software development and personality types". IT professional, vol. 12, no. 1, pp. 6-13, 2010.

[34] K. S. Choi, F. P. Deek and I. Im. "Exploring the underlying aspects of pair programming: The impact of personality". Information and Software Technology, vol. 50, no. 11, pp. 1114-1126, 2008.

[35] V. Galpin, I. Sanders, H. Turner and B. Venter. "Computer self-efficacy, gender, and educational background in South Africa". Technology and Society Magazine, IEEE, vol. 22, no. 3, pp. 43-48, 2003.

[36] M. L. Lyons. "The DP psyche". Datamation, vol. 31, no. 16 , pp. 103-110, 1985.

[37] R. T. Turley and J. M. Bieman. "Competencies of exceptional and nonexceptional software engineers". Journal of Systems and Software, vol. 28, no. 1, pp. 19-38, 1995.

[38] S. R. Porter and P. D. Umbach. "College major choice: An analysis of person-environment fit". Research in Higher Education, vol. 47, no. 4, pp. 429-449, 2006.

[39] J. L. Rosenbloom, R. A. Ash, B. Dupont and L. Coder. "Why are there so few women in information technology? Assessing the role of personality in career choices". Journal of Economic Psychology, vol. 29, no. 4 , pp. 543-554, 2008.

[40] J. L. Wynekoop and D. B. Walz. "Investigating traits of top performing software developers". Information Technology \& People, vol. 13, no. 3, pp. 186-195, 2000.

[41] T. W. Ferratt and L. E. Short. "Are information systems people different: an investigation of motivational differences". MIS Quarterly, pp. 377-387, 1986.

[42] P. Blignaut and A. Naude. "The influence of temperament style on a student's choice of and performance in a computer programming course". Computers in Human Behavior, vol. 24, no. 3, pp. 1010-1020, 2008.

[43] D. P. Darcy and M. Ma. "Exploring individual characteristics and programming performance: Implications for programmer selection". In System Sciences, 2005. HICSS'05. Proceedings of the 38th Annual Hawaii International Conference on, pp. 314a-314a. IEEE, 2005 .

[44] A. Sodiya, H. Longe, S. Onashoga, O. Awodele and L. Omotosho. "An Improved Assessment of Personality Traits in Software Engineering." Interdisciplinary Journal of Information, Knowledge $\& 5$ Management, vol. 2, 2007.

[45] S. T. Acuña, M. Gómez and N. Juristo. "How do personality, team processes and task characteristics relate to job satisfaction and software quality?" Information and Software Technology, vol. 51, no. 3, pp. 627-639, 2009.

[46] K. Behrenbruch, M. Söllner, J. M. Leimeister and L. Schmidt. "Understanding Diversity-The Impact of
Personality on Technology Acceptance". In HumanComputer Interaction-INTERACT 2013, pp. 306-313. Springer, 2013.

[47] S. Devaraj, R. F. Easley and J. M. Crant. "Research note-how does personality matter? Relating the fivefactor model to technology acceptance and use". Information Systems Research, vol. 19, no. 1, pp. 93-105, 2008.

[48] K. Moore and J. C. McElroy. "The influence of personality on Facebook usage, wall postings, and regret". Computers in Human Behavior, vol. 28, no. 1, pp. 267-274, 2012.

[49] J. W. Lounsbury, R. S. Studham, R. P. Steel, L. W. Gibson, A. W. Drost, Y. Dwivedi, B. Lal, M. Williams, S. Schneberger and M. Wade. "Personality traits and career satisfaction of information technology professionals". Handbook of research on contemporary theoretical models in information systems, pp. 529-543, 2009.

[50] P. Alexander, V. Pieterse and H. Lotriet. "A comparison of computing and non-computing students' personalities based on the Five-Factor Model". In European Conference on Information Systems. 2011.

[51] C. Maier. "Personality Within Information Systems Research: A Literature Analysis". ECIS 2012 Proceedings, 2012.

[52] J. C. McElroy, A. R. Hendrickson, A. M. Townsend and S. M. DeMarie. "Dispositional factors in internet use: personality versus cognitive style". MIS quarterly, pp. 809-820, 2007.

[53] E. H. Vick. Implementing lexical and creative intentionality in synthetic personality. Ph.D. thesis, University of Central Florida Orlando, Florida, 2005.

[54] P. J. Howard and J. M. Howard. "The Big Five Quickstart: An Introduction to the Five-Factor Model of Personality for Human Resource Professionals." Tech. rep., Center for Applied Cognitive Studies (CentACS), 1995.

[55] P. M. Alexander, M. Holmner, H. H. Lotriet, M. C. Matthee, H. Pieterse, S. Naidoo, H. Twinomurinzi and D. Jordaan. "Factors affecting career choice: Comparison between students from computer and other disciplines". Journal of Science Education and Technology, vol. 20, no. 3, pp. 300-315, 2011.

[56] R. W. Lent, S. D. Brown, R. Talleyrand, E. B. McPartland, T. Davis, S. B. Chopra, M. S. Alexander, V. Suthakaran and C.-M. Chai. "Career choice barriers, supports, and coping strategies: College students' experiences". Journal of Vocational Behavior, vol. 60, no. 1, pp. 61-72, 2002.

[57] P. Alexander and H. Twinomurinzi. "Changing career choice factors as the economic environment changes". In Proceedings of the South African Institute for Computer Scientists and Information Technologists Conference, pp. 295-305. ACM, 2012.

[58] S. Beyer. "Gender Differences and Intra-Gender Differences amongst Management Information Systems Students." Journal of Information Systems Education, vol. 19, no. 3, 2008.

[59] K. A. Walstrom, T. P. Schambach, K. T. Jones and W. J. Crampton. "Why are students not majoring in information systems?" Journal of Information Systems Education, vol. 19, no. 1, 2008. 
[60] W. Zhang. "Why IS: Understanding Undergraduate Students' Intentions to Choose an Information Systems Major." Journal of Information Systems Education, vol. 18, no. 4, 2007.

[61] R. B. Johnson and A. J. Onwuegbuzie. "Mixed methods research: A research paradigm whose time has come". Educational researcher, vol. 33, no. 7, pp. 14-26, 2004.

[62] P. Alexander and V. Pieterse. "Indications of personality trait difference between ICT and other students". In 18th European Conference of Information Systems (ECIS 2010). 2010.

[63] R. W. Lent, S. D. Brown and G. Hackett. "Toward a unifying social cognitive theory of career and academic interest, choice, and performance". Journal of vocational behavior, vol. 45, no. 1, pp. 79-122, 1994.

[64] Y. Lee and S. J. Lee. "The Competitiveness of the Information Systems Major: An Analytic Hierarchy Process." Journal of Information Systems Education, vol. 17, no. 2, 2006.

[65] L. Seymour, M. Hart, P. Haralamous, T. Natha and C.-W. Weng. "Inclination of scholars to major in information systems or computer science". In Proceedings of the 2004 annual research conference of the South African Institute of Computer Scientists and Information Technologists on IT research in developing countries, pp. 97-106. South African Institute for Computer Scientists and Information Technologists, 2004. 